\title{
Clinical efficacy of intermittent pressure augmented-retrograde cerebral perfusion
}

\author{
Hidehito Endo, MD, Hiroshi Kubota, MD, Hiroshi Tsuchiya, MD, Akihiro Yoshimoto, MD, \\ Yu Takahashi, MD, Yusuke Inaba, MD, and Kenichi Sudo, MD
}

\begin{abstract}
Objective: During aortic surgery under hypothermic circulatory arrest, retrograde cerebral perfusion (RCP) is commonly used as a cerebroprotective method to extend the duration of circulatory arrest safely. Kitahori and colleagues described a novel protocol of RCP using intermittent pressure augmented (IPA)-RCP in 2005. The aim of the present study was to determine the clinical effectiveness of this novel protocol.
\end{abstract}

\begin{abstract}
Methods: A total of 20 consecutive patients undergoing total replacement of the aortic arch were assigned to a conventional RCP $(n=10)$ or an IPA-RCP group $(n=10)$. Cerebral perfusion was provided at a continuous venous pressure of $25 \mathrm{~mm} \mathrm{Hg}$ in the conventional RCP, and venous pressure was intermittently provided at 20 $\mathrm{mm} \mathrm{Hg}$ for 120 seconds and at $45 \mathrm{~mm} \mathrm{Hg}$ for 30 seconds in the IPA-RCP group. The clinical outcomes were compared between the 2 groups. Regional cerebral oxygen saturation $\left(\mathrm{rSO}_{2}\right)$ was measured using near infrared spectroscopy every 10 minutes from the beginning of RCP initiation. To represent the brain oxygen consumption, the decline ratio of $\mathrm{rSO}_{2}$ was calculated.
\end{abstract}

Results: There was no surgical mortality or major neurologic complications in either group. The interval from the end of surgery to full wakefulness was significantly shorter in the IPA-RCP group ( $85 \pm 64$ minutes) than in the conventional RCP group $(310 \pm 282$ minutes; $P<.05)$. Although the initial $\mathrm{rSO}_{2}$ value did not show significant difference in both groups, the $\mathrm{rSO}_{2}$ with IPA-RCP was greater than that with conventional RCP from 10 to 70 minutes $(P<.05)$. The decline ratio of $\mathrm{rSO}_{2}$ was lower in the IPA-RCP group than in the RCP perfusion group at all points $(P<.05)$.

Conclusions: IPA-RCP might provide more homogenous cerebral perfusion and a more effective oxygen supply to the brain with better clinical results than conventional RCP. (J Thorac Cardiovasc Surg 2013;145:768-73)

During aortic surgery under hypothermic circulatory arrest (HCA), the cerebroprotective method uses retrograde cerebral perfusion (RCP) to more safely extend the duration of HCA. Usui and colleagues ${ }^{1}$ reported that a venous pressure of $25 \mathrm{~mm} \mathrm{Hg}$ was the optimal condition for RCP to avoid brain injury. However, some reports have suggested that $\mathrm{RCP}$ at a perfusion pressure of less than 25 to $30 \mathrm{~mm} \mathrm{Hg}$ provides very limited blood flow to the brain and minimal or no brain protection. Furthermore, other investigators have reported that the use of RCP with greater venous pressures results in good outcomes without any significant complications. ${ }^{2,3}$ Therefore, the optimal method to protect the brain during HCA remains to be established.

Kitahori and colleagues ${ }^{4}$ reported a novel method of RCP (intermittent pressure augmented-retrograde cerebral perfusion [IPA-RCP]) that controlled venous pressure at 15

From the Department of Cardiovascular Surgery, Kyorin University, Tokyo, Japan. Disclosures: Authors have nothing to disclose with regard to commercial support. Received for publication Oct 24, 2011; revisions received Jan 27, 2012; accepted for publication March 12, 2012; available ahead of print April 12, 2012.

Address for reprints: Hidehito Endo, MD, Department of Cardiovascular Surgery, Kyorin University 6-20-2, Sinkawa, Mitaka-shi, Tokyo 181-8611 Japan (E-mail: ehidehito@hotmail.com).

0022-5223/\$36.00

Copyright (c) 2013 by The American Association for Thoracic Surgery doi:10.1016/j.jtcvs.2012.03.015 $\mathrm{mm} \mathrm{Hg}$ with intermittent pressure augmented to $45 \mathrm{~mm}$ $\mathrm{Hg}$. These investigators demonstrated the efficacy of this strategy in an animal model. ${ }^{4}$

We applied IPA-RCP in clinical cases because cardiopulmonary bypass (CPB) can be simply driven and the risk of brain injury did not increase in animal models. We speculated that IPA-RCP could protect the brain more effectively, because it preserves intracerebral oxygen more completely by way of intermittent augmented venous pressure than conventional RCP (cRCP) in clinical cases.

The aim of the present study was to use IPA-RCP in clinical cases and examine the clinical efficacy of IPA-RCP compared with cRCP.

\section{METHODS \\ Patients}

A total of 20 consecutive patients who underwent total replacement of the aortic arch with RCP without a concomitant procedure for the management of thoracic aortic disease at Kyorin University from January 2005 to October 2008 were examined. The institutional review board approved the study, and all patients provided informed consent. Of the 20 patients, 11 were men and 9 were women (average age, $69.6 \pm 14.9$ years; range, 27-83 years). The thoracic aortic disease consisted of type A acute aortic dissection in 5 patients and true aortic aneurysm in 15 . Surgery was required on an emergency basis for 6 patients and was elective for 14 patients. During the observation period, 46 patients underwent aortic arch surgery at our institution. Of these, 26, 10, and 10 patients underwent isolated total replacement of the aortic arch, partial replacement of the aortic arch, and 


\section{Abbreviations and Acronyms \\ $\mathrm{cRCP}=$ conventional retrograde cerebral perfusion \\ $\mathrm{CPB}=$ cardiopulmonary bypass \\ HCA = hypothermic circulatory arrest \\ IPA-RCP = intermittent pressure augmented- retrograde cerebral perfusion \\ $\mathrm{RCP}=$ retrograde cerebral perfusion \\ $\mathrm{rSO}_{2}=$ regional cerebral oxygen saturation \\ SVC = superior vena cava}

augmented at $45 \mathrm{~mm} \mathrm{Hg}$ for 30 seconds and decreased to $20 \mathrm{~mm} \mathrm{Hg}$ for 120 seconds.

At the end of RCP, the venous pressure was augmented to 40 to $50 \mathrm{~mm}$ $\mathrm{Hg}$ for 180 seconds to de-air and flush the debris and switched to antegrade perfusion using a side branch of the graft.

\section{Cerebral Oxygen Saturation Monitoring}

The regional cerebral oxygen saturation $\left(\mathrm{rSO}_{2}\right)$ was measured using near-infrared spectroscopy (TOS-96; Tostec, Tokyo, Japan). The TOS-96 consists of a high-performance microprocessor controlling unit and a sensor probe. The sensor probe had 6 light emitting diodes with low-power pulsed laser lights at wavelengths of 760 and $850 \mathrm{~nm}$ and 2 silicon photo diodes. The sensor probe was applied to the forehead over the frontal lobe lateral to the midline to avoid the superior sagittal sinus. Real-time spectroscopic data reflecting the oxyhemoglobin and deoxyhemoglobin levels were continuously measured. The $\mathrm{rSO}_{2}$ (capillary vessel oxygen consumption in the cerebral cortex) was calculated using the oxyhemoglobin and deoxyhemoglobin levels.

a combination of other procedures (eg, valvular surgery, coronary artery bypass grafting), respectively. Of those who underwent isolated total replacement of the aortic arch, 2 had received a combination of cRCP and IPA-RCP, and in 4, the regional cerebral oxygen saturation could not be measured using near-infrared spectroscopy because of noise. These 6 patients were excluded from the present study. Thus, 20 consecutive patients, including 10 who had undergone cRCP from 2005 to 2006 and 10 who had undergone IPA-RCP from 2007 to 2008, were examined (Table 1).

\section{Anesthesia and Surgical Procedures}

General anesthesia was performed using total intravenous anesthesia. Induction was achieved with intravenous midazolam hydrochloride, fentanyl citrate, and vecuronium bromide. The maintenance anesthetic agents included propofol and fentanyl citrate.

A median sternotomy was performed. Cardiopulmonary bypass (CPB) was established after the administration of heparin $(3 \mathrm{mg} / \mathrm{kg})$. The arterial cannulation site was the femoral artery, and venous cannulas were placed in the superior vena cava (SVC) and inferior vena cava. The left ventricle was vented through the right superior pulmonary vein. Surgical tape was placed around the SVC. Myocardial protection was achieved with antegrade cold blood cardioplegia.

During perfusion cooling, the $\mathrm{pH}$ and partial pressure of carbon dioxide were maintained by $\mathrm{pH}$-stat principles, at 7.30 to 7.50 for $\mathrm{pH}$ and 30 to 50 $\mathrm{mm} \mathrm{Hg}$ for partial pressure of carbon dioxide, corrected for temperature. The core temperature was measured by way of a sensor on the tympanic membrane.

When the core temperature had decreased to $18^{\circ}$ to $22^{\circ} \mathrm{C}$, an open distal anastomosis was performed using 4-branched prosthetic grafts. The arch vessels were individually transected, and the left subclavian artery and left common carotid artery were reconstructed. After reconstruction of these 2 arch vessels, circulatory arrest and RCP were terminated. The prosthetic graft was clamped, and antegrade arterial flow was restarted using a side branch of the prosthetic graft, resulting in restoration of the normal core temperature. The innominate artery was reconstructed. Finally, open proximal anastomosis was performed, and CPB was weaned. All anesthetic agents were terminated at the end of surgery, and the patients were transferred to the intensive care unit.

\section{RCP Protocol}

The patients' temperature was lowered by core cooling. CPB was stopped after the target temperature was reached, and RCP was started. In the CPB circuit, the inferior vena cava cannula was clamped, and oxygenated blood was perfused into the SVC cannula by way of a recirculation circuit. Central venous pressure was measured by a catheter inserted to the SVC.

In the cRCP group, the central venous pressure was provided at $25 \mathrm{~mm}$ $\mathrm{Hg}$. In the IPA-RCP group, the central venous pressure was intermittently

\section{Examination Methods}

The clinical outcomes were compared between the 2 groups. The clinical outcomes included the following parameters: age, body surface area, perfusion time, aortic crossclamp time, minimal core temperature, circulatory arrest time, RCP time, blood volume loss, blood transfusion, operation time, anesthetic time, dose of fentanyl citrate and propofol, and interval from the end of surgery to full wakefulness. The $\mathrm{rSO}_{2}$ was measured every 10 minutes from the initiation of $\mathrm{RCP}(\mathrm{n}=0,10,20,30,40,50,60,70,80$ minutes). The decline ratio of $\mathrm{rSO}_{2}$ was calculated as follows: $\left[\mathrm{rSO}_{2}\right.$ $(\mathrm{n}=0)-\mathrm{rSO}_{2}(\mathrm{n}=x$ minutes $\left.) / \mathrm{rSO}_{2}(0)\right] \times 100 \%$. The $\mathrm{rSO}_{2}$ value and the decline ratio of $\mathrm{rSO}_{2}$ were compared in both groups.

The primary endpoints were in-hospital death, neurologic complications, and discharge.

\section{Statistical Analysis}

The data were evaluated using SAS, version 5.0 (SAS Institute, Cary, $\mathrm{NC}$ ). The results are expressed as the mean \pm SD. Statistical significance between the 2 groups was determined using the Mann-Whitney nonparametric test. $P<.05$ was defined as statistically significant.

\section{RESULTS \\ Clinical Outcomes}

The patients in the IPA-RCP group were significantly younger than those in the cRCP group, mainly because 1 patient in IPA-RCP group was 27 years old (Table 2). No significant difference were found in the anesthetic time or total dosage of anesthetic agents between the 2 groups. The interval from the end of surgery to full wakefulness was shorter in the IPA-RCP group than in the cRCP group. No surgical mortality or major neurologic complications occurred in either group.

\section{$\mathbf{r S O}_{2}$ Value at Each Measurement Point}

The initial $\mathrm{rSO}_{2}$ was not significantly different in the 2 groups (Table 3). However, the $\mathrm{rSO}_{2}$ in the IPA-RCP group was significantly greater than that in the cRCP group when measured at 10 to 70 minutes. Only 2 patients required IPARCP for longer than 80 minutes, and statistical analysis was not possible. 
TABLE 1. Patient characteristics

\begin{tabular}{|c|c|c|c|}
\hline Characteristic & cRCP & IPA-RCP & $P$ value \\
\hline Patients (n) & 10 & 10 & \\
\hline Age (y) & & & .02 \\
\hline Mean \pm SD & $77.0 \pm 5.8$ & $62.2 \pm 17.7$ & \\
\hline Range & $68-83$ & $27-81$ & \\
\hline Body surface area $\left(\mathrm{m}^{2}\right)$ & & & NS \\
\hline Mean \pm SD & $1.55 \pm 0.14$ & $1.62 \pm 0.11$ & \\
\hline Range & $1.25-1.70$ & $1.45-1.81$ & \\
\hline \multicolumn{4}{|l|}{ Gender (n) } \\
\hline Male & 6 & 5 & \\
\hline Female & 4 & 5 & \\
\hline \multicolumn{4}{|l|}{ Preoperative diagnosis (n) } \\
\hline Dissection of aorta & 1 & 4 & \\
\hline Thoracic aortic aneurysm & 9 & 6 & \\
\hline \multicolumn{4}{|l|}{ Timing of surgery (n) } \\
\hline Elective & 8 & 6 & \\
\hline Emergency & 2 & 4 & \\
\hline
\end{tabular}

\section{Decline Ratio of $\mathbf{r S O}_{2}$}

The curve of $\mathrm{rSO}_{2}$ during RCP is illustrated in Figure 1. In the cRCP group, the $\mathrm{rSO}_{2}$ decreased sharply just the start of RCP and then gradually decreased until the end of RCP. In the IPA-RCP group, the $\mathrm{rSO}_{2}$ gradually decreased during low venous pressure and increased during intermittent augmented venous pressure. In both procedures, the $\mathrm{rSO}_{2}$ curve decreased sharply just after the resumption of antegrade cerebral perfusion by way of a side branch of the graft, but then it gradually increased back to its initial level. Thus, the decline ratio of $\mathrm{rSO}_{2}$ was significantly lower in the IPA-RCP group than in the cRCP group at each measurement point (Figure 2 and Table 4 ).

\section{DISCUSSION}

$\mathrm{RCP}$ was originally described as an emergency treatment of a massive air embolism during $\mathrm{CPB},{ }^{5}$ and Ueda and colleagues ${ }^{6}$ characterized the efficacy of RCP during HCA in 1990. The method for RCP was described with the presumption that a venous pressure of $25 \mathrm{~mm} \mathrm{Hg}$ was the optimal condition for RCP to avoid brain injury, ${ }^{1,7,8}$ and thus, RCP has been performed under continuous venous pressure of $25 \mathrm{~mm} \mathrm{Hg}$. However, some investigators have reported that RCP did not provide neurologic protection at a venous pressure of less than $25 \mathrm{~mm} \mathrm{Hg}$ in several clinical and experimental studies, ${ }^{9-12}$ and other studies have indicated that high venous pressure might cause brain edema. ${ }^{2,13}$ In contrast, Li and colleagues ${ }^{3}$ and Estrera and colleagues ${ }^{2}$ reported that a venous pressure greater than $30 \mathrm{~mm} \mathrm{Hg}$ resulted in better tissue oxygenation without tissue edema in an animal model and did not result in brain injury in clinical cases. Thus, it is still unclear whether RCP with a venous pressure of $25 \mathrm{~mm} \mathrm{Hg}$ is optimum and provides appropriate neurologic protection.
TABLE 2. Clinical outcomes

\begin{tabular}{|c|c|c|c|}
\hline Outcome & cRCP & IPA-RCP & $\begin{array}{c}P \\
\text { value }\end{array}$ \\
\hline Perfusion time (min) & & & NS \\
\hline Mean \pm SD & $253.7 \pm 37.4$ & $220.7 \pm 29.8$ & \\
\hline Range & $197-323$ & $191-291$ & \\
\hline Aortic crossclamp time (min) & & & NS \\
\hline Mean \pm SD & $132.0 \pm 14.1$ & $135.2 \pm 17.8$ & \\
\hline Range & $104-158$ & $100-160$ & \\
\hline Minimal core temperature $\left({ }^{\circ} \mathrm{C}\right)$ & & & NS \\
\hline Mean \pm SD & $15.0 \pm 1.0$ & $15.1 \pm 1.6$ & \\
\hline Range & $13.4-16.9$ & $12.3-16.8$ & \\
\hline RCP time (min) & & & NS \\
\hline Mean \pm SD & $76.4 \pm 8.3$ & $68.1 \pm 8.0$ & \\
\hline Range & $64-87$ & $55-77$ & \\
\hline \multicolumn{4}{|l|}{ In SVC cannula during $\mathrm{RCP}^{*}$} \\
\hline Hemoglobin (mg/dl) & & & NS \\
\hline Mean \pm SD & $6.5 \pm 0.5$ & $6.9 \pm 0.4$ & \\
\hline Range & $6.0-7.4$ & $6.0-7.5$ & \\
\hline $\begin{array}{l}\text { Concentration of oxygen } \\
\qquad(\mathrm{mm} \mathrm{Hg})\end{array}$ & & & NS \\
\hline Mean \pm SD & $392.4 \pm 35.4$ & $349.6 \pm 65.4$ & \\
\hline Range & $346.1-448.7$ & $218.3-435.2$ & \\
\hline Blood volume loss (mL) & & & NS \\
\hline Mean \pm SD & $1262.5 \pm 831.6$ & $990.3 \pm 534.3$ & \\
\hline Range & $570-3173$ & $442-2407$ & \\
\hline Blood transfusion $(\mathrm{U})$ & & & NS \\
\hline Mean $\pm \mathrm{SD}$ & $10.5 \pm 5.6$ & $10.2 \pm 8.8$ & \\
\hline Range & $3-20$ & $0-26$ & \\
\hline Operation time (min) & & & NS \\
\hline Mean \pm SD & $507 \pm 87$ & $455 \pm 60$ & \\
\hline Range & $405-672$ & $384-565$ & \\
\hline Anesthetic time (min) & & & NS \\
\hline Mean \pm SD & $660 \pm 73$ & $572 \pm 70$ & \\
\hline Range & $550-799$ & 499-694 & \\
\hline Dose of fentanyl citrate $(\mathrm{mL})$ & & & NS \\
\hline Mean \pm SD & $1080 \pm 210$ & $1090 \pm 288$ & \\
\hline Range & $900-1600$ & $700-1600$ & \\
\hline Dose of propofol (mg) & & & NS \\
\hline Mean \pm SD & $2249 \pm 416$ & $2414 \pm 638$ & \\
\hline Range & $1365-2801$ & $1455-3447$ & \\
\hline $\begin{array}{l}\text { Interval from surgery end to } \\
\text { full wakefulness (min) }\end{array}$ & & & .03 \\
\hline Mean $\pm \mathrm{SD}$ & $310 \pm 282$ & $85 \pm 64$ & \\
\hline Range & 10-785 & $3-200$ & \\
\hline Intubation time (min) & & & NS \\
\hline Mean \pm SD & $1950 \pm 1964$ & $1087 \pm 903$ & \\
\hline Range & $625-5510$ & $0-2905$ & \\
\hline ICU stay (d) & & & NS \\
\hline Mean \pm SD & $12.3 \pm 16.2$ & $5.7 \pm 1.4$ & \\
\hline Range & $4-55$ & $4-8$ & \\
\hline Hospital stay (d) & & & .02 \\
\hline Mean \pm SD & $58.5 \pm 32.0$ & $30.4 \pm 14.1$ & \\
\hline Range & $16-121$ & $19-60$ & \\
\hline
\end{tabular}

$\overline{c R C P \text {, Conventional retrograde cerebral perfusion; IPA-RCP, intermittent pressure }}$ augmented-retrograde cerebral perfusion; $N S$, not significant; $S D$, standard deviation; $R C P$, retrograde cerebral perfusion; $S V C$, superior vena cava; $I C U$, intensive care unit. *At the start of RCP. 
TABLE 3. $\mathrm{rSO}_{2}$ values

\begin{tabular}{|c|c|c|c|}
\hline Measurement point (min) & $\operatorname{cRCP}(\%)$ & IPA-RCP (\%) & $P$ value \\
\hline 0 & & & NS \\
\hline Mean \pm SD & $72.7 \pm 6.6$ & $73.1 \pm 4.2$ & \\
\hline Range & $62.5-87.5$ & $65.7-80.0$ & \\
\hline 10 & & & .04 \\
\hline Mean \pm SD & $66.5 \pm 8.0$ & $70.9 \pm 5.0$ & \\
\hline Range & $53.4-82.4$ & $61.3-79.5$ & \\
\hline 20 & & & .02 \\
\hline Mean \pm SD & $63.6 \pm 7.7$ & $68.2 \pm 5.3$ & \\
\hline Range & $51.1-79.1$ & $58.8-77.2$ & \\
\hline 30 & & & .02 \\
\hline Mean \pm SD & $60.6 \pm 8.3$ & $66.7 \pm 5.0$ & \\
\hline Range & $46.8-76.0$ & $57.4-77.5$ & \\
\hline 40 & & & .04 \\
\hline Mean \pm SD & $59.1 \pm 9.4$ & $65.3 \pm 4.9$ & \\
\hline Range & $44.9-75.0$ & $55.2-75.9$ & \\
\hline 50 & & & .04 \\
\hline Mean \pm SD & $57.6 \pm 10.5$ & $64.6 \pm 4.6$ & \\
\hline Range & $39.2-73.3$ & $56.0-74.6$ & \\
\hline 60 & & & .002 \\
\hline Mean \pm SD & $54.9 \pm 10.9$ & $64.7 \pm 3.7$ & \\
\hline Range & $33.4-72.9$ & $58.8-73.9$ & \\
\hline 70 & & & .007 \\
\hline Mean \pm SD & $54.3 \pm 10.9$ & $63.6 \pm 3.9$ & \\
\hline Range & $32.0-72.6$ & $57.3-67.8$ & \\
\hline 80 & & & - \\
\hline Mean \pm SD & $53.5 \pm 11.8$ & $62.9 \pm 4.2$ & \\
\hline Range & $30.8-67.8$ & $59.9-65.8$ & \\
\hline
\end{tabular}

$r \mathrm{SO}_{2}$, Regional cerebral oxygen saturation; $c R C P$, conventional retrograde cerebral perfusion; IPA-RCP, intermittent pressure augmented-retrograde cerebral perfusion; $N S$, not significant; $S D$, standard deviation.

Kitahori and colleagues ${ }^{4}$ subsequently described a novel protocol of RCP with intermittent pressure augmentation and examined the efficacy of this protocol in a canine model. They reported that cRCP was associated with a sudden loss of cerebral perfusion pressure with conversion of antegrade to retrograde perfusion, resulting in collapse of the cortical veins and increased resistance to opening of the cerebrovenous vessels. Further, they showed that venous pressure of less than $25 \mathrm{~mm} \mathrm{Hg}$ was insufficient to promote opening of the cerebral microvessels by observing changes in diameters of the retinal vessels. In contrast, a continuously high venous pressure of RCP was associated with an increased risk of perfusioninduced brain injury. In their protocol of RCP, the venous pressure was controlled at $15 \mathrm{~mm} \mathrm{Hg}$ and was augmented to $45 \mathrm{~mm} \mathrm{Hg}$ quickly and then decreased again to the baseline level of $15 \mathrm{~mm} \mathrm{Hg}$ as soon as it reached 45 $\mathrm{mm} \mathrm{Hg}$ every 30 seconds throughout the 60 -minute duration of HCA. They concluded that the RCP pressure was important to overcome the venous resistance of the capillaries and to maintain microvessel patency. Intermittent high pressure effectively overcame the maldistribution associated with RCP without brain damage. This novel method might provide effective neurologic protection during aortic surgery. ${ }^{4}$

In the present study, IPA-RCP was applied clinically by modifying the original experimental protocol. As the first point of modification, the maximal venous pressure was the same as that required to open the cerebral microvessels, and the minimum venous pressure was changed to $20 \mathrm{~mm}$ $\mathrm{Hg}$. The reasons for the modification were that a venous pressure of $20 \mathrm{~mm} \mathrm{Hg}$ was reported to provide metabolic support for the brain. ${ }^{7}$ The second point of modification was that the duration of augmented pressure was set at 30 seconds. The original protocol was to decrease the venous pressure to $15 \mathrm{~mm} \mathrm{Hg}$ as soon as it had reached $45 \mathrm{~mm}$ $\mathrm{Hg}$. We considered this would result in a burden and a risk of carelessness because of the complicated and perpetual CPB driving.

In the present study, the dose of anesthetic agents and clinical outcomes were similar between the cRCP and IPA-RCP groups; however, the interval from the end of surgery to full wakefulness was shorter in the IPA-RCP group than in the cRCP group. Previous animal studies have suggested that IPA-RCP results in good recovery from anesthesia and less neurologic damage compared with cRCP and HCA. ${ }^{4}$ The reason for the shorter interval to wakefulness in the IPA-RCP group might have been related to the mainly neuroprotective effect provided by the homogeneous cerebral perfusion and better oxygen supply.

The efficacy of IPA-RCP was assessed through measurement of frontal lobe $\mathrm{rSO}_{2}$ in the present study. This was achieved using near-infrared spectroscopy (TOS-96; Tostec), because most attenuation of near-infrared light in human cerebral tissues results from absorption by deoxyhemoglobin and deoxyhemoglobin. ${ }^{13}$ The determination of $\mathrm{rSO}_{2}$ is an easy method to assess the real-time adequacy of cerebral perfusion during deep hypothermic time-restricted aortic arch surgery. ${ }^{13,14}$ However, $\mathrm{rSO}_{2}$ measurements can vary with temperature, hemoglobin level, oxygenated blood, and oxygen consumption in the cerebral tissue and anatomy. ${ }^{15-17}$ Regardless, no significant difference was found in the minimal core temperature or the concentration of oxygen and hemoglobin in the perfused blood to the SVC during RCP between the cRCP and IPA-RCP groups in the present study.

The $\mathrm{rSO}_{2}$ curve showed immediate recovery with every venous pressure augmentation, and it decreased when the augmentation ceased. Furthermore, the decline ratio of $\mathrm{rSO}_{2}$ was significantly lower in the IPA-RCP group than in the cRCP group at each measurement point. The essential effect of IPA-RCP might be a temporary increase in cerebral oxygen saturation and augmentation of the decline ratio of $\mathrm{rSO}_{2}$ during RCP. These observations support the notion of the "bottom raising effect" of IPA-RCP described in our case reports ${ }^{14,18}$ and can be explained in that a venous pressure of $45 \mathrm{~mm} \mathrm{Hg}$ opens up the intracranial 

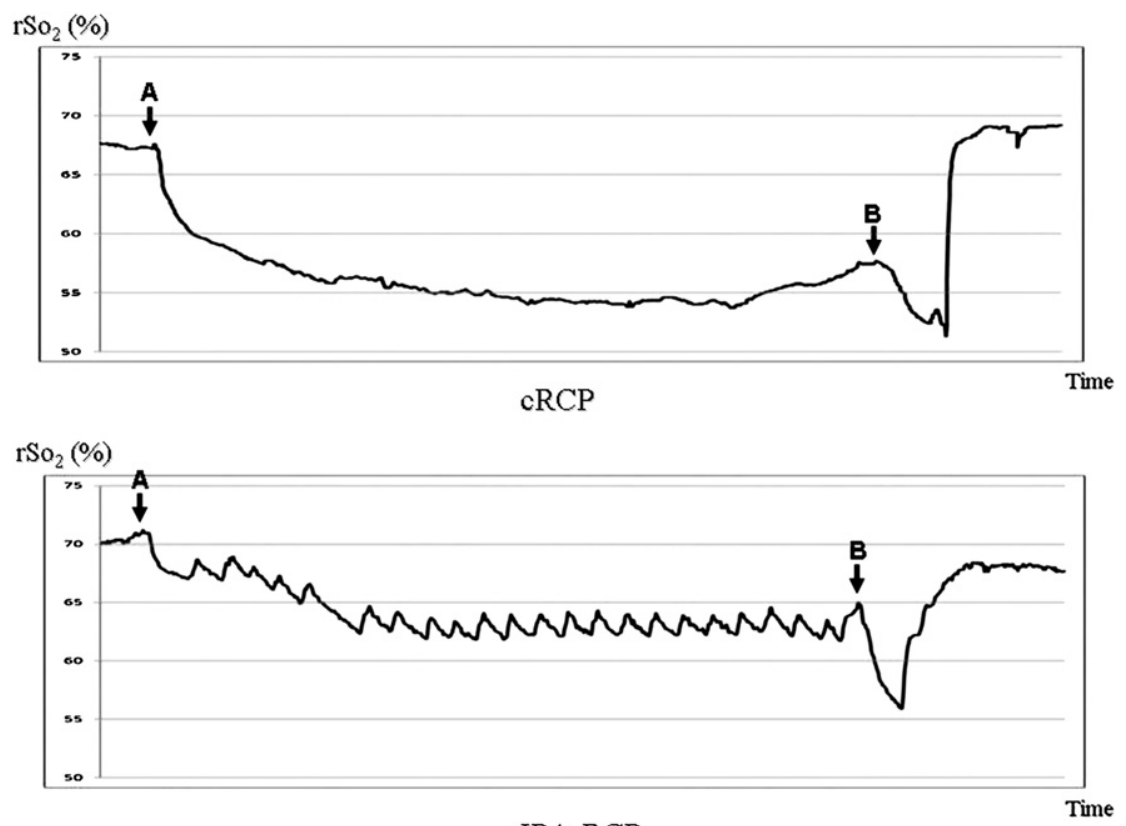

IPA-RCP

FIGURE 1. Typical waveform of regional cerebral oxygen saturation $\left(\mathrm{rSO}_{2}\right)$ measured by near-infrared spectroscopy during retrograde cerebral perfusion $(R C P)$ in each group. (Upper) Conventional RCP $(c R C P)$ group. (Lower) Intermittent pressure augmented-retrograde cerebral perfusion $(I P A-R C P)$ group. $A$ indicates start of hypothermic circulatory arrest $(H C A)$ and RCP; and $B$, end of HCA and RCP.

microvessels, allowing perfusion of the peripheral brain with oxygenated blood, and a venous pressure of $25 \mathrm{~mm}$ $\mathrm{Hg}$ was inadequate for cerebral circulation.

The present study had limitations in patients and method. First, the sample size was rather small, and the study design was nonrandomized and retrospective. To reduce these limitations and bias, 2 groups of consecutive patients who had undergone simple total aortic arch replacement were selected and compared. Second, measuring $\mathrm{rSO}_{2}$ using nearinfrared spectroscopy is simple but has the disadvantage

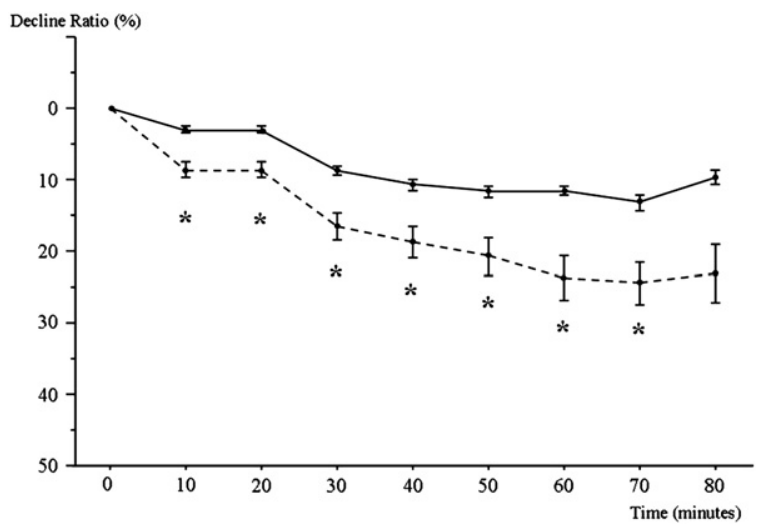

FIGURE 2. Serial changes in mean \pm standard deviation decline ratios of regional cerebral oxygen saturation $\left(\mathrm{rSO}_{2}\right)$ in conventional retrograde cerebral perfusion $(c R C P)$ and intermittent pressure augmented-retrograde cerebral perfusion (IPA-RCP) groups. Solid line, IPA-RCP group; dashed line, cRCP group. $* P<.05$. that flow is measured only in the frontal region. Therefore, the homogeneity of cerebral blood flow distribution could not be evaluated. Third, Tau protein and S-100, which are indicators of cerebrospinal injury, were not measured postoperatively and the cerebrospinal fluid pressure was not measured during RCP. The Tau protein levels were significantly lower in the IPA-RCP group than in the cRCP group in an animal model, and the cerebrospinal fluid pressure did not significantly differ between the 2 groups. ${ }^{4}$ An additional clinical study is needed. Fourth, the actual cerebral microcirculation was not evaluated because the retinal vessels were not observed. Experimental studies have demonstrated that $45 \mathrm{~mm} \mathrm{Hg}$ of venous pressure is required to maintained patency of the retinal veins and arteries. ${ }^{4,19}$ Observing the retinal vessels during IPA-RCP will provide more information to recognize the mechanism of brain protection clinically. Fifth, preoperative and postoperative cognitive functions were not assessed as clinical outcomes. Several reports have indicated that the incidence of transient brain dysfunction is significantly greater in patients after $\mathrm{RCP}^{20,21}$ The present study was preliminary; thus, more extensive clinical experience is essential, and additional analysis of these parameters will help to verify the clinical utility of IPA-RCP.

\section{CONCLUSIONS}

IPA-RCP might provide better cerebral protection than cRCP during aortic arch surgery under HCA. 
TABLE 4. Decline ratio of $\mathrm{rSO}_{2}$

\begin{tabular}{lccr}
\hline Measurement point $(\mathbf{m i n})$ & $\mathbf{c R C P}(\boldsymbol{\%})$ & IPA-RCP $(\%)$ & $\boldsymbol{P}$ value \\
\hline 10 & & & .0004 \\
$\quad$ Mean \pm SD & $8.65 \pm 5.03$ & $3.1 \pm 2.0$ & \\
$\quad$ Range & $0.7-18.5$ & $0.3-6.79$ & \\
20 & & & .005 \\
$\quad$ Mean \pm SD & $12.6 \pm 6.0$ & $6.8 \pm 3.1$ & \\
$\quad$ Range & $2.2-22.9$ & $2.7-12.4$ & \\
30 & & & .002 \\
$\quad$ Mean \pm SD & $16.6 \pm 7.9$ & $8.8 \pm 2.9$ & \\
$\quad$ Range & $4.2-32.4$ & $3.1-13.9$ & \\
40 & & & .01 \\
$\quad$ Mean \pm SD & $18.8 \pm 9.6$ & $10.7 \pm 3.3$ & \\
$\quad$ Range & $5.1-34.8$ & $5.1-17.7$ & \\
50 & & & .01 \\
$\quad$ Mean \pm SD & $20.8 \pm 11.9$ & $11.7 \pm 3.6$ & \\
$\quad$ Range & $7.4-44.2$ & $6.7-18.8$ & \\
60 & & & .0004 \\
$\quad$ Mean \pm SD & $23.7 \pm 13.3$ & $11.5 \pm 2.8$ & \\
Range & $7.2-52.4$ & $7.6-18.1$ & \\
70 & & & \\
$\quad$ Mean \pm SD & $24.5 \pm 13.1$ & $13.1 \pm 3.7$ & \\
$\quad$ Range & $10.6-54.4$ & $9.1-21.1$ & \\
80 & & & \\
Mean \pm SD & $23.1 \pm 14.8$ & $9.7 \pm 1.4$ & \\
Range & $9.5-56.0$ & $8.7-10.7$ & \\
\hline
\end{tabular}

$\overline{r S O_{2} \text {, Regional cerebral oxygen saturation; } c R C P \text {, conventional retrograde cerebral }}$ perfusion; IPA-RCP, intermittent pressure augmented-retrograde cerebral perfusion; $S D$, standard deviation.

\section{References}

1. Usui A, Oohara K, Liu TL, Murase M, Tanaka M, Takeuchi E, et al. Determination of optimum retrograde cerebral perfusion conditions. J Thorac Cardiovasc Surg. 1994;107:300-8.

2. Estrera AL, Garami Z, Miller CC III, Sheinbaum R, Huynh TTT, Porat EE, et al. Determination of cerebral blood flow dynamics during retrograde cerebral perfusion using power M-mode transcranial Doppler. Ann Thorac Surg. 2003;76:704-10.

3. Li Z, Yang L, Jackson M, Summers R, Donnelly M, Deslauriers R, et al. Increased pressure during retrograde cerebral perfusion in an acute porcine model improves brain tissue perfusion without increase in tissue edema. Ann Thorac Surg. 2002;73:1514-21.

4. Kitahori K, Takamoto S, Takayama H, Suematsu Y, Ono M, Motomura N, et al. A novel protocol of retrograde cerebral perfusion with intermittent pressure augmentation for brain protection. J Thorac Cardiovasc Surg. 2005;130:363-70.

5. Mills NL, Ochsner JL. Massive air embolism during cardiopulmonary bypass: causes, prevention, and management. J Thorac Cardiovasc Surg. 1980;80:708-17.
6. Ueda M, Miki S, Kusuhara K, Okita Y, Tahata T, Yamanaka K. Surgical treatment of aneurysm or dissection involving the ascending aorta and aortic arch, utilizing circulatory arrest and retrograde cerebral perfusion. J Cardiovasc Surg (Torino). 1990;31:553-8.

7. Nojima T, Magara T, Nakajima Y, Waterida S, Onoe M, Sugita T, et al. Optimal perfusion pressure for experimental retrograde cerebral perfusion. J Cardiac Surg. 1994;9:548-59.

8. Oohara K, Usui A, Murasa M, Tanaka M, Abe T. Regional cerebral tissue blood flow measured by the colored microsphere method during retrograde cerebral perfusion. J Thorac Cardiovasc Surg. 1995;109:772-9.

9. Boeckxstaens CJ, Flameng WJ. Retrograde cerebral perfusion does not perfuse the brain in nonhuman primates. Ann Thorac Surg. 1995;60:319-28.

10. Te J, Ryner LN, Kozlowski P, Yang L, Del Bigio MR, Sun J, et al. Retrograde cerebral perfusion results in flow distribution abnormalities and neuronal damage: a magnetic resonance imaging and histopathological study in pigs. Circulation. 1998;98(suppl II):II-313-8.

11. Ehrlich MP, Hagl C, McCullough JN, Zhang N, Shiang H, Bodian C, et al. Retrograde cerebral perfusion provides negligible flow through brain capillaries in the pig. J Thorac Cardiovasc Surg. 2001;122:331-8.

12. Bonser RS, Wong CH, Harrington D, Pagano D, Wilkes M, Clutton-Brock T, et al. Failure of retrograde cerebral perfusion to attenuate metabolic changes associated with hypothermic circulatory arrest. J Thorac Cardiovasc Surg. 2002; 123:943-50.

13. Oshikiri N, Watanabe T, Saitou H, Ijima Y, Minowa T, Inui Y, et al. Retrograde cerebral perfusion: experimental approach to brain oedema. Perfusion. 1999;14: 257-62.

14. Kubota H, Tonari K, Endo H, Tsuchiya H, Yoshino H, Sudo K. Total aortic arch replacement under intermittent pressure-augmented retrograde cerebral perfusion. J Cardiothrac Surg. 2010;5:97.

15. Ogino H, Ueda Y, Sugita T, Morioka K, Sakakibara Y, Matsubayashi K, et al Monitoring of regional cerebral oxygenation by near-infrared spectroscopy during continuous retrograde cerebral perfusion for aortic arch surgery. Eur J Cardiothorac Surg. 1998;14:415-8.

16. Kamihira S, Ohgi S. Evaluation of cerebral oxygen saturation assessed by nearinfrared spectroscopy during hypothermic circulatory arrest. J Jpn Coll Angiol. 2003;43:363-7.

17. Orihashi K, Sueda T, Okada K, Imai K. Near-infrared spectroscopy for monitoring cerebral ischemia during selective cerebral perfusion. Eur J Cardiothorac Surg. 2004;26:907-11.

18. Kubota H, Takamoto S, Yoshino H, Kitahori K, Kawata M, Tonari K, et al. Clinical application of intermittent pressure-augmented retrograde cerebral perfusion. Ann Thorac Surg. 2010;90:1340-3.

19. Kawata M, Takamoto S, Kitahori K, Tsukihara H, Morota T, Ono M, et al. Intermittent pressure augmentation during retrograde cerebral perfusion under moderate hypothermia provides adequate neuroprotection: an experimental study. $J$ Thorac Cardiovasc Surg. 2006;132:80-8.

20. Okita Y, Minatoya K, Tagusari O, Ando M, Nagatsuka K, Kitamura S. Prospective comparative study of brain protection in total aortic arch replacement: deep hypothermic circulatory arrest with retrograde cerebral perfusion or selective antegrade cerebral perfusion. Ann Thorac Surg. 2001;72:72-9.

21. Reich DL, Uysal S, Ergin MA, Bodian CA, Hossain S, Griepp RB. Retrograde cerebral perfusion during thoracic aortic surgery and late neuropsychological dysfunction. Eur J Cardiothorac Surg. 2001;19:594-600. 